\title{
Desempenho ponderal de bovinos Nelore suplementados com fontes alternativas de fósforo ${ }^{1}$
}

\author{
Guilherme Cazerta Lemos ${ }^{2}$, Rogério Magnoli Costa ${ }^{3}$, Manoel Garcia Neto ${ }^{4}$ \\ e Pedro Malafaia ${ }^{5 *}$
}

\begin{abstract}
Lemos G.C., Costa R.M., Neto M.G. \& Malafaia P. 2013. [Weight gain of Nelore cattle supplemented with different phosphorus sources.] Desempenho ponderal de bovinos Nelore suplementados com fontes alternativas de fósforo. Pesquisa Veterinária Brasileira 33(2):188-192. Departamento de Nutrição Animal e Pastagem, Instituto de Zootecnia, Universidade Federal Rural do Rio de Janeiro, Seropédica, RJ 23851-970, Brazil. E-mail: malafaia_ufrrj@yahoo.com.br

Weight gain and possible interference of fluoride on animal health was investigated in Nellore cattle supplemented during 866 days with alternative sources of phosphorus with different phosphorus:fluor (P:F) ratios. The five treatments were: (1) Negative control (NC, without any supplemental P), (2) dicalcium phosphate (DCP 120:1, DCP 30:1 and DCP 10:1), (3) monodicalcium phosphate (MDCP 60:1), (4) triple superphosphate (TSF 30:1), and (5) cajati rock phosphate (RP 10:1). We used 49 oxen weaned with 8 months of age and an average weight of $230 \mathrm{~kg}$, distributed into seven paddocks with water and mineral mixture formulated without P. A standard diet consisting of sugar cane bagasse $(0.03 \% \mathrm{P})$ as roughage and a concentrate containing $0.239 \% \mathrm{P}$ was provided on $1 \%$ of live weight to allow a weight gain of about $0.50 \mathrm{~kg} /$ day. Until day 134, there was no statistical difference between the various groups, including the treatment $\mathrm{NC}$ which received no supplemental phosphorus in the diet and gained weight of $71.6 \mathrm{~kg}$ or $0.633 \mathrm{~kg} /$ day. After 866 days of confinement (2.37 years), the oxen supplemented with dicalcium phosphate standard (120:1) gained less weight than those supplemented with sources MDCP 60:1, DCP 30:1 and TSF $30: 1$. Up to one year of supplementation with dicalcium phosphate artificially fluoridated with $\mathrm{NaF}$ or with rock phosphate did not result in damage to health or in weight gain of the animals. Analyses of phosphorus in bones showed statistical difference between treatments, and group NC that did not receive any supplemental P showed the lowest values. The concentration of fluoride in bones proved to be closely related to the amount of fluoride available in the sources used. As the ratio P:F in the diet decreased, characteristic signs related to dental fluorosis became more evident, and the animals that received $\mathrm{P}$ supplies with 10:1 ratio showed at the end of the experiment permanent malformed incisor teeth, brittle and whitish stained.
\end{abstract}

INDEX TERMS: Fluorosis, dicalcium phosphate, rock phosphate, superphosphate, phosphoric supplementation, cattle.

\footnotetext{
${ }^{1}$ Recebido em 6 de dezembro de 2012.

Aceito para publicação em 31 de dezembro de 2012.

${ }^{2}$ Zootecnista, Rua Francisco Braga 197, Bairro Bandeiras, Araçatuba, SP 16015-560, Brasil. E-mail: guilherme.cazerta@gmail.com

${ }^{3}$ Zootecnista, Exito Rural Consultoria em Pecuária, Av. Mário Covas 2747, Araçatuba, SP 16072-005. E-mail: rogerio@exitorural.com.br

${ }^{4}$ Faculdade de Medicina Veterinária, Universidade Estadual Paulista (Unesp), Rua Clóvis Pestana 793, Araçatuba, SP 16050-680.

${ }^{5}$ Departamento de Nutrição Animal e Pastagem, Instituto de Zootecnia, Universidade Federal Rural do Rio de Janeiro (UFRRJ), Seropédica, RJ 23851970, Brasil.*Autor para correspondência: malafaia_ufrrj@yahoo.com.br
}

RESUMO.- 0 desempenho produtivo e a possível interferência do flúor sobre a saúde dos animais foram investigados em bovinos Nelore suplementados, por 866 dias, com distintas fontes alternativas de fósforo com diferentes relações fósforo:fluor (P:F). Os tratamentos experimentais foram: Controle negativo (CONTNEG, sem qualquer suplementação com P), fosfato bicálcico (FB 120:1, FB 30:1 e FB 10:1), fosfato monobicálcico (FMBC 60:1), superfosfato triplo (SFT 30:1) e fosfato de rocha de Cajati (FR 10:1). Foram utilizados 49 novilhos, desmamados aos oito meses de ida- 
de, castrados e com $230 \mathrm{~kg}$ de peso médio, distribuídos em sete piquetes com água e mistura mineral formulada sem P. A dieta padrão foi feita com bagaço de cana $(0,03 \%$ de $\mathrm{P})$ como volumoso e um concentrado contendo $0,239 \%$ de $\mathrm{P}$ oferecido na base de $1 \%$ do peso dos animais para permitir um ganho de peso aproximado de $0,50 \mathrm{~kg} /$ dia. Até o dia 134, não houve diferença estatística entre os diversos lotes, inclusive para o tratamento CONTNEG, que não recebeu fósforo suplementar na dieta e ganhou 71,6 kg de peso ou 0,633 kg/dia. Após 866 dias de confinamento (2,37 anos), os animais suplementados com o fosfato bicálcico padrão (120:1) ganharam menos peso que os suplementados com as fontes FMCB 60:1, FB 30:1 e SFT 30:1. Até um ano de suplementação fosfórica com fosfato bicálcico padrão (120:1) artificialmente fluoretado com $\mathrm{NaF}$ ou com o fosfato de rocha não se detectou danos à saúde ou ao ganho de peso dos animais. As análises de fósforo nos ossos mostraram diferença estatística apenas entre o tratamento CONTNEG e os que tinham fosfato bicálcico. As concentrações de flúor nos ossos se mostraram intimamente associadas à quantidade de flúor disponível nas fontes utilizadas. Conforme a proporção P:F na dieta foi diminuindo, características relacionadas à fluorose dentária ficaram mais evidentes, sendo que os animais que receberam fontes com relação 10:1, apresentaram, ao final do experimento, dentes incisivos permanentes mal formados, quebradiços e com manchas esbranquiçadas.

TERMOS DE INDEXAÇÃO: Bovinos, fluorose, fosfato bicálcico, fosfato de rocha, superfosfato triplo, suplementação fosfórica.

\section{INTRODUÇÃO}

A pecuária de corte brasileira caracteriza-se predominantemente pela exploração e produção de animais em regime de pasto, pois o país está localizado em região tropical, onde a maioria das terras disponíveis para a atividade são as áreas de cerrado e de campos naturais, caracterizadas pela baixa fertilidade do solo (Gomide 1994). No Brasil, cerca de $80 \%$ das terras agricultáveis têm baixos teores de fósforo (Butolo 2002), de tal maneira que as gramíneas, introduzidas nessas regiões, possuem baixas concentrações desse mineral, o que determina a necessidade, maior ou menor, de suplementação fosfórica aos animais, para que estes tenham desempenho compatível e justifique a viabilidade econômica da atividade.

Por ser um dos minerais em maior proporção nas misturas minerais, dada a sua importância metabólica, e por constituir-se no insumo de maior impacto no custo final dos suplementos, o fósforo é objeto de inúmeros estudos com a finalidade de buscar fontes alternativas que atendam às exigências dos animais (para ganho e reprodução), que não sejam prejudiciais (tanto à saúde animal quanto a humana) e que não impliquem em contaminação ambiental.

Há o fósforo orgânico, presente nos ossos ou na constituição dos vegetais e de seus sub-produtos, e o fósforo inorgânico, de origem ígnea ou sedimentar, presente nas rochas fosfáticas, conhecidas por apatita. As rochas sedimentares apresentam altos teores de contaminantes como o flúor (F), metais pesados e até elementos radioativos. As jazidas brasileiras têm sua formação de rochas ígneas consideradas de elevada qualidade devido aos baixos teores de flúor, alumínio e metais pesados (Butolo 2002). A qualidade da apatita é que determina a qualidade do ácido fosfórico, principal matéria-prima na produção de fertilizantes e dos fosfatos destinados à alimentação. Para alimentação animal, o ácido fosfórico é purificado para remover os elementos indesejáveis, resultando num produto sem potencial de toxidade. A pesquisa relacionada ao emprego de fontes de $P$ não convencionais para a alimentação animal, como os fertilizantes fosfatados e os fosfatos de rocha (in natura) tem sido realizada há anos no Brasil (Rosa \& Cardoso 1987, Rosa et al. 1988, Vitti et al. 1989, Dayrell et al. 1990, Lopes et al. 1990, Veloso 1991). Porém, nesses estudos, as fontes de fósforo foram sempre aquelas disponíveis no mercado e eram confrontadas com o fosfato bicálcico como ingrediente de referência. Por outro lado, é necessário investigar, não apenas as fontes alternativas de fósforo, mas também diversas relações fósforo:flúor (P:F), pois é sabida a variabilidade dessa relação nas distintas fontes fosfóricas. Existe a preocupação de que essas fontes alternativas possam ser usadas de forma indiscriminada, visto que a legislação que limitava a utilização sofreu diversas modificações, culminando com a liberação do uso de fontes antes proibidas.

A Portaria da Secretaria de Desenvolvimento Rural, SDR no 20, de 6 de junho de 1997, claramente limitava o uso de fontes de fósforo na alimentação animal, com os artigos $2^{\circ}, 3^{\circ}$ e $5^{\circ}$ que versava respectivamente sobre a utilização de fontes de fósforo registradas, as indicações da solubilidade do fósforo, nível máximo de $\mathrm{F}$ e o limite máximo de 2000ppm de F, desde que a relação P:F mínima fosse 60:1 (Brasil 1997). Porém, com a publicação da Portaria no 6, de 04 de fevereiro de 2000, o Ministério da Agricultura, Pecuária e Abastecimento revoga os artigos $2^{\circ}$ e $3^{\circ}$ da Portaria SDR no 20 e extingue a relação mínima de P:F, mantendo apenas o limite máximo de $2000 \mathrm{ppm}$ de $\mathrm{F}$ para as misturas minerais de pronto uso, o que libera, portanto, a comercialização e utilização de outras fontes de fósforo para alimentação animal (Brasil 2000).

Assim, essas alterações ministeriais estimularam a produção deste estudo com a finalidade de avaliar o desempenho de bovinos submetidos à ingestão prolongada de diferentes fontes de fósforo com diversas relações fósforo:flúor (P:F) na sua composição e ainda, analisar a interferência do $\mathrm{F}$ no desempenho dos animais, com dietas formuladas para simular um crescimento similar ao verificado em regime de pasto em animais confinados.

\section{MATERIAL E MÉTODOS}

O estudo foi conduzido nas instalações do Setor Experimental de Zootecnia da Universidade Estadual Paulista (Unesp), Campus de Araçatuba, SP. A fase experimental teve início no dia 28.04.2003 e término em 30.11.2005, totalizando 947 dias. Os primeiros 81 dias foram destinados à adaptação dos animais à dieta e às instalações. Após o período de adaptação (18.07.03), os animais foram sorteados e distribuídos em sete tratamentos (Quadro 1). Utilizaram-se 49 novilhos Nelores, recém desmamados, castrados, com oito meses de idade e cerca de $230 \mathrm{~kg}$ de peso vivo (PV), obtidos de um lote de 300 animais, provenientes de uma mesma proprie- 
dade e selecionados com critério de menor desvio padrão da média do lote para esta variável. 0 peso vivo médio dos os animais, após o período de adaptação era de $266,4 \mathrm{~kg}$. Os animais foram distribuídos em sete piquetes com $140 \mathrm{~m}^{2}$ (7x20) cada, dispostos lado a lado, dotados de cochos com $1 \mathrm{~m}$ linear por animal e bebedouros de concreto. A mistura mineral foi formulada sem fósforo e foi disponibilizada ad libitum, em cochos separados. Os animais foram distribuídos de forma aleatória dentro dos tratamentos, compondo um delineamento inteiramente casualisado, com sete tratamentos e sete repetições.

As dietas foram calculadas para oferecer fósforo para mantença e para um ganho de peso de aproximadamente $0,50 \mathrm{~kg} /$ dia por animal, seguindo recomendações do NRC (1996). Esse ganho de peso permite simular os ganhos médios normalmente observados em animais criados em regime de pasto, o que resultou em maior tempo de exposição dos animais ao flúor contido nas fontes fornecidas. 0 fósforo necessário para a mantença e o ganho de peso foi proveniente de fontes permitidas pela legislação brasileira, fornecidas em quantidade suficiente para garantir uma ingestão diária de 4 g de P/animal, e da dieta padrão, responsável pelo fornecimento de uma pequeníssima quantidade de P (Quadro 2).

Os tratamentos foram compostos por quatro diferentes fontes de fósforo contendo diferentes relações fósforo:flúor (P:F); a saber: Fosfato bicálcico padrão (FB 120:1), fosfato monobicálcico (FMBC 60:1), superfosfato triplo (SFT 30:1) e fosfato de rocha (FR 10:1) (Quadro 1). 0 fosfato bicálcico padrão (120:1), rotineiramente utilizado como fonte de P no Brasil, foi intencionalmente contaminado com fluoreto de sódio $(\mathrm{NaF})$ para atingirem níveis de $\mathrm{F}$ que fossem semelhantes aos que se encontram no superfosfato triplo (relação $\mathrm{P}: \mathrm{F}=30: 1$ ) e no fosfato de rocha (relação $P: F=10: 1$ ). Dessa forma, foram criados dois tratamentos à base de fosfato bicálcico contaminado com F, os denominados FB 30:1 e FB 10:1 (Quadro 1). No FMBC 60:1, SFT 30:1 e no FB 120:1, o flúor se apresenta, principalmente, na forma de fluoreto de cálcio $\left(\mathrm{CaF}_{2}\right)$, proveniente da rocha fosfática utilizada como matéria prima na produção desses produtos. Segundo Rosa \& Cardoso (1987), os níveis de tolerância ao F são baseados na toxicidade sob a forma de $\mathrm{NaF}$, que é cerca de duas vezes mais tóxico que o $\mathrm{CaF}_{2}$ encontrado nas rochas fosfáticas e em seus derivados.

O concentrado, cuja composição encontra-se na Quadro 2, foi fornecido numa proporção de $1 \%$ do peso vivo dos animais e o volumoso, representado pelo bagaço de cana hidrolisado, foi oferecido em quantidades ajustadas por meio do monitoramento das sobras diárias, que deveriam ficar entre 5 a $10 \%$ do ofertado. 0

Quadro 1. Descrição das fontes de fósforo, relação P:F e quantidades usadas diariamente para ganho de $0,50 \mathrm{~kg} /$ dia por animal e respectivos consumos de fósforo e flúor provenientes destes produtos

\begin{tabular}{|c|c|c|c|c|c|c|}
\hline \multirow{2}{*}{$\begin{array}{l}\text { Trata- } \\
\text { mentos }\end{array}$} & \multirow[t]{2}{*}{ Fontes de $\mathrm{P}$} & \multicolumn{5}{|c|}{ Quantidades fornecidas } \\
\hline & & $\begin{array}{l}\% \text { P na } \\
\text { Fonte }\end{array}$ & $\begin{array}{l}\text { Relação } \\
\text { P:F }\end{array}$ & $\begin{array}{l}\text { da fonte } \\
\text { (g/cab.d) }\end{array}$ & $\begin{array}{c}\text { de } \mathrm{P}^{\mathrm{a}} \\
\text { (g/cab.d) }\end{array}$ & $\begin{array}{c}\text { de F } \\
\text { (g/cab.d) }\end{array}$ \\
\hline CONTNEG & $x x x$ & 0 & 0 & 0 & 0 & 0 \\
\hline FB 120:1 & fosfato bicálcico & 16,29 & $120: 1$ & 25,0 & 4,07 & 0,034 \\
\hline MCB 60:1 & $\begin{array}{l}\text { fosfato monobi- } \\
\text { cálcico }\end{array}$ & 17,74 & $60: 1$ & 23,0 & 4,08 & 0,068 \\
\hline FB 30:1 & fosfato bicálcico & b 14,85 & $30: 1$ & 27,0 & 4,01 & 0,134 \\
\hline SFT 30:1 & $\begin{array}{l}\text { super fosfato tri- } \\
\text { plo }\end{array}$ & $-17,47$ & $30: 1$ & 23,0 & 4,02 & 0,134 \\
\hline FB 10: & fosfato bicálcico ${ }^{\circ}$ & ${ }^{c} 16,03$ & $10: 1$ & 25,0 & 4,01 & 0,401 \\
\hline FR 10:1 & fosfato de rocha & 15,01 & $10: 1$ & 27,0 & 4,08 & 0,408 \\
\hline
\end{tabular}

Quadro 2. Composição do concentrado e teor de fósforo dos ingredientes da dieta

\begin{tabular}{lcc}
\hline \multicolumn{1}{c}{ Ingredientes } & \% no concentrado & $\%$ P (\%MS) \\
\hline Casquinha de soja & 91,104 & 0,257 \\
Gordura protegida & 4,442 & 0,055 \\
Glúten de milho & 1,117 & 0,307 \\
Uréia & 3,337 & 0,000 \\
TOTAL & 100,00 & 0,239 \\
Bagaço de cana* & xxx & 0,030
\end{tabular}

consumo de concentrado foi recalculado mensalmente, segundo o desempenho médio de cada grupo.

A dieta total, exceto a fonte suplementar de fósforo, foi fornecida aos animais às $8 \mathrm{~h}$ e às $16 \mathrm{~h}$ em quantidades iguais. As fontes de P foram oferecidas apenas no trato da manhã e, para que fossem consumidas na sua totalidade e de forma homogênea, foram misturadas com $0,25 \mathrm{~kg}$ de fubá/animal e oferecidas sobre a dieta. O lote CONTNEG recebeu apenas as $250 \mathrm{~g}$ de fubá sem a fonte de fósforo suplementar e serviu, por toda a fase experimental, para a verificação da real necessidade de suplementação de fósforo.

No inicio do experimento os animais foram pesados a cada 15 dias e posteriormente a cada 28 dias, sendo que a rotina de pesagem se iniciava com a suspensão da alimentação na tarde anterior. Na manhã seguinte, após criteriosa calibração da balança, os animais eram conduzidos por lote, até o curral de manejo, onde eram pesados individualmente e posteriormente retornavam ao piquete de confinamento. Para padronizar a curva de ganho de peso dos animais por tratamento, o experimento foi subdividido em períodos de aproximadamente 90 dias. Os animais foram abatidos no final do experimento (947 dias), independente do peso vivo.

Para análise de $\mathrm{P}$ e F nos ossos, utilizaram-se as primeiras falanges dos metacarpos. Esse material foi desengordurado em extrator Soxhlet e levado à estufa ventilada a $55^{\circ} \mathrm{C} / 72 \mathrm{~h}$, em seguida, foram triturado em moinho de bola, para depois se proceder à secagem definitiva em estufa a $105^{\circ} \mathrm{C}$ por $24 \mathrm{~h}$. A determinação dos teores de cinzas foi feita em forno mufla a $600^{\circ} \mathrm{C} / 4 \mathrm{~h}$ e as concentrações de fósforo foram estimadas por colorimetria, de acordo com a metodologia descrita por Silva \& Queiroz (2002). O flúor ósseo foi analisado por potenciometria.

As variáveis avaliadas no experimento foram o ganho de peso nos diversos períodos e os teores de fósforo e flúor nos ossos. Os dados obtidos foram analisados pelo programa SAS-Versão Release 6.12 (SAS, 1996), onde se efetuou a análise de variância das variáveis avaliadas e para comparação entre as médias dos tratamentos foi utilizado o teste Duncan.

\section{RESULTADOS E DISCUSSÃO}

Os pesos médios dos animais são mostrados na Tabela 3 e permitem perceber que no início do experimento havia uma boa homogeneidade de peso entre os grupos experimentais. Até o dia 134, não houve diferença estatística entre os diversos lotes, inclusive para o tratamento CONTNEG, que não recebeu fósforo suplementar na dieta e ganhou 334,4 $\mathrm{kg}(71,6 \mathrm{~kg}$ de peso ou $0,633 \mathrm{~kg} / \mathrm{dia})$. Os animais que receberam o fosfato bicálcico padrão (120:1) ganharam 7,2 kg a mais do que os do grupo CONTNEG e 13,5 kg a menos que os que foram suplementados com o fosfato de rocha, que foram os animais que mais ganharam peso até os 134 dias de confinamento (Tabela 3). Desses resultados iniciais, pode-se concluir que a suplementação fosfórica não interferiu estatisticamente no desempenho dos animais até os 134 dias de confinamento. De forma similar, Dayrell et al. (1990) tam- 
Quadro 3. Idade, duração do período sob confinamento e desempenho ponderal dos animais em função dos tratamentos experimentais

\begin{tabular}{|c|c|c|c|c|c|c|c|c|}
\hline \multirow{2}{*}{\multicolumn{2}{|c|}{$\begin{array}{l}\text { Idade Dias con- } \\
\text { (dias) finados }\end{array}$}} & \multirow[b]{2}{*}{ CONTNEG } & \multicolumn{6}{|c|}{ Pesos médios (em kg)** } \\
\hline & & & FB120:1 & MCB60:1 & FB30:1 & SFT30:1 & FB10:1 & FR10:1 \\
\hline $351^{*}$ & 1 & 262 & $263,6^{-a}$ & 267,7 & 265,4 & 270,9 & ,1) & $268,7^{\mathrm{a}}$ \\
\hline 397 & 43 & $298,3^{\mathrm{a}}(24,9)$ & $302,6^{a}(32,3)$ & $303,4^{\mathrm{a}}(21,7)$ & $301,0^{\text {a }}(33,9)$ & $308,3^{\mathrm{a}}(22,8)$ & $300,3^{\mathrm{a}}(22,4)$ & $308,1^{\mathrm{a}}(24,3)$ \\
\hline 485 & 134 & $334,4^{\mathrm{a}}(26,0)$ & $341,6^{a}(35,3)$ & $348,3^{\mathrm{a}}(26,0)$ & $351,3^{\mathrm{a}}(39,6)$ & $351,1^{\mathrm{a}}(28,6)$ & $342,1^{\mathrm{a}}(24,7)$ & $\mathbf{3 5 5}, \mathbf{1}^{\mathrm{a}}(30,0)$ \\
\hline 569 & 224 & 369 & $(33,4)$ & $400,1^{\mathrm{ab}}$ & $416,8^{a}$ & $416,3^{\mathrm{a}} \mathrm{c}$ & $389,5^{\mathrm{b}}(24,8)$ & 407,7 \\
\hline 736 & 364 & 419 & 441, & $450,5^{\mathrm{b}}(28,6)$ & 479,3 & 477 & $445,3^{\mathrm{b}}$ & $448,7^{\mathrm{b}}$ \\
\hline 830 & 47 & & 50 & $\mathbf{5 1 7 , 0 ^ { \mathrm { b } }}$ & & 54 & $\mathbf{5 0 4}$ & $504,2^{\text {b }}$ \\
\hline 110 & 76 & 497 & 622, & 637 & 65 & 674 & 61 & $572,5^{\mathrm{d}}($ \\
\hline $1217^{\#}$ & 866 & $511,5^{\mathrm{d}}(29,5)$ & $648,7^{\mathrm{c}}(12,1)$ & $662,5^{\text {bc }}(16,8)$ & $678,0^{\text {ab }}(31,0)$ & $699,0^{a}(29,8)$ & $637,0^{c}(38,7)$ & $624,7^{\mathrm{c}}(23,0)$ \\
\hline
\end{tabular}

* Idade média dos animais no início da fase experimental.

\# Idade média dos animais no final do experimento e respectivos pesos médios finais por tratamento.

** Médias, seguidas de mesma letra nas linhas, não diferem entre si pelo teste de Duncan a 5\% de probabilidade de erro. Valores entre parênteses referem-se aos desvios-padrões das médias.

bém não encontraram diferenças nos ganhos de peso de novilhos suplementados com fosfato de tapira e fosfato bicálcico em 168 dias de confinamento. Dessa forma, fica evidente que nas distintas situações onde o consumo de concentrados, formulados com os principais ingredientes disponíveis no Brasil, for superior a $1 \%$ do peso dos animais, os bovinos deveriam ser suplementados com pequenas quantidades de $\mathrm{P}$ ou até mesmo não serem suplementados. Tal inferência se aplica aos confinamentos de curta duração (<120dias) e aos denominados "animais de elite", que são criados desde a tenra idade com dietas ricas em grãos e seus subprodutos e ingerem volumosos (silagens, capineiras ou fenos) de boa qualidade. 0 fósforo ingerido em excesso, além de ser um enorme desperdício de dinheiro e de um recurso mineral não renovável, causa eutrofização de rios e lagos e propicia a formação de urólitos nos animais. Vale relatar que o concentrado utilizado neste estudo não é feito de forma rotineira nas fazendas! Ele foi formulado propositadamente com ingredientes que permitissem fechar exigências em proteina e energia e que provessem a menor quantidade possível de $P$.

Aos 224 e 364 dias de confinamento, as diferenças nos ganhos de peso entre os tratamentos começaram ficar mais evidentes (Quadro 3) e, novamente, os animais que receberam o fosfato bicálcico padrão (120:1) ganharam menos peso do que os que foram suplementados com as fontes FMCB 60:1, FB 30:1, SFT 30:1, FB 10:1 e FR 10:1 (Quadro $3)$. Os animais que não receberam suplementação fosfórica (CONTNEG) foram aqueles que ganharam menos peso nas pesagens de 224 e 364 de confinamento.

Aos 475 dias, apenas os animais do grupo CONTNEG não pesaram mais de $500 \mathrm{~kg}$, sendo os grupos FB 30:1 e SFT 30:1 aqueles que mais peso ganharam (Quadro 3). Por fim, após 866 dias (2,37 anos), os animais suplementados com o fosfato bicálcico padrão (120:1) ganharam menos peso que os suplementados com as fontes FMCB 60:1, FB 30:1 e SFT 30:1 (Quadro 3).

Possivelmente, tais diferenças nos ganhos de peso estejam relacionadas com a biodisponibilidade do fósforo nas distintas fontes, que em ordem decrescente, é de $90-95 \%$ para o SFT e de 25-50\% para o fosfato de rocha (Baruselli, 2005; Vitti et al. 1989 e 1991). Devido aos resultados encontrados, O FMBC 60:1 provavelmente esteja em situação intermediária quanto à solubilidade do $\mathrm{P}$.
Embora os animais não suplementados com P (CONTNEG) ganhassem $248,6 \mathrm{~kg}$ nos 866 dias de confinamento $(0,287 \mathrm{~kg} / \mathrm{dia})$, eles exibiram alteração comportamental caracterizada pela ingestão de terra e pedras, caracterizando o apetite depravado citado por Conrad et al. (1985), que pode ser um sinal da deficiência de P. Esses animais possuíam os pêlos ásperos e sem brilho e eram bastante apáticos; sinais também sugestivos da deficiência de P (Tokarnia et al., 2010). Devido ao baixo ganho de peso, ao fato de que os animais recebiam mistura mineral adequada em Na e Co, e a ingestão de quantidade suficiente de fibra fisicamente efetiva, pode-se caracterizar tal alotriofagia como decorrente da deficiência sub-clínica de P.

Para atingir peso superior a $500 \mathrm{~kg}$, os animais do lote CONTNEG levaram 391 dias a mais que os demais grupos experimentais (Quadro 3). Em condições de pasto, esse tempo a mais pode ser representativo quando se contabiliza os gastos envolvidos para manter os animais nas propriedades. Fato semelhante pode ser observado com frequência em diversas regiões do Brasil, onde os animais apresentam estrutura óssea e desenvolvimento corporal comprometido, devido às pastagens de baixíssima qualidade e às extensas áreas dos pastos que comprometem a ingestão diária dos suplementos minerais, o que provoca deficiências, principalmente a de fósforo.

Na Tabela 4, são apresentadas as concentrações de fósforo nos ossos dos animais nos diversos tratamentos. Os resultados das análises de $\mathrm{P}$ mostraram diferença estatística $(\mathrm{P}<0,0254)$ apenas entre o tratamento CONTNEG e os tratamentos FB 120:1, FB 30:1 e FB 10:1. Ainda no Quadro 4 , os valores de $\mathrm{P}$ nos ossos dos animais CONTNEG mostram que, apesar de não receberem $P$ suplementar, a quantidade de P disponível na dieta padrão foi priorizada para a formação óssea e a manutenção do animal e comprometeu, portanto, significativamente o ganho de peso (Quadro 3).

Os resultados das análises de flúor nos ossos se mostraram intimamente associados à quantidade de flúor ingerida pelos animais em função das distintas relações P:F oferecidas (Quadro 4). Dessa forma, a maior concentração de F ósseo foi verificada no tratamento FB 10:1 e foi conseqüência da contaminação intencional do fosfato bicálcico pelo NaF. $\mathrm{O}$ FR 10:1, que tem o Fluor na forma de $\mathrm{CaF}_{2}$, teve uma concentração de F ósseo inferior ao FB 10:1 (Quadro 4). Nos trata- 
Quadro 4. Concentração de fósforo (P) e flúor (F) nos ossos dos animais

\begin{tabular}{lcc}
\hline Tratamentos & $\mathrm{P}(\mathrm{g} / \mathrm{kg})$ & $\mathrm{F}(\mathrm{mg} / \mathrm{kg})$ \\
\hline CONTNEG & $83,3^{\mathrm{b}}$ & $843,2^{\mathrm{d}}$ \\
FB 120:1 & $90,8^{\mathrm{a}}$ & $1324,1^{\mathrm{d}}$ \\
MCB 60:1 & $89,8^{\mathrm{ab}}$ & $1623,3^{\mathrm{d}}$ \\
FB 30:1 & $93,6^{\mathrm{a}}$ & $2990,4^{\mathrm{c}}$ \\
SFT 30:1 & $89,4^{\mathrm{ab}}$ & $3518,8^{\mathrm{c}}$ \\
FB 10:1 & $95,2^{\mathrm{a}}$ & $6904,3^{\mathrm{a}}$ \\
FR 10:1 & $89,1^{\mathrm{ab}}$ & $5698,9^{\mathrm{b}}$ \\
Probabilidade & 0,025 & 0,0001 \\
CV $(\%)$ & 4,8 & 15,2 \\
\hline
\end{tabular}

Valores, seguidos da mesma letra, na mesma coluna, não diferem entre si pelo teste de Duncan a 5\% de probabilidade.

mentos FB 30:1 e SFT 30:1, a concentração de flúor nos ossos foi inferior $(\mathrm{P}<0,0001)$ aos tratamentos FR 10:1 e FB 10:1 e superior aos FMBC 60:1, FB 120:1 e CONTNEG (Tabela 4). Godoy et al. (2000) encontraram resultados semelhantes em trabalho conduzido na Venezuela, com bovinos mestiços. Em experimentos em que bovinos de corte e de leite estiveram expostos ao flúor por longo período, a retenção de flúor no osso foi proporcional à concentração deste elemento na dieta (NRC, 1980). Sinais clínicos de fluorose óssea foram observados em um dos animais do tratamento FR 10:1, já no final da fase experimental. Esse animal apresentou espessamento nas articulações proximais dos metacarpos e metatarsos e considerável dificuldade de locomoção; foi sacrificado, pois evitava permanecer em pé ou locomover-se até mesmo para alimentar-se. Rosa \& Cardoso (1987) também descreveram tais sintomas como característicos de fluorose.

Em todos os tratamentos, com exceção do CONTNEG, foram observados animais com crescimento excessivo dos cascos, inclusive com casos de quebra das pinças. A presença desse fato nos diversos tratamentos possivelmente seja resultado do tempo que os animais ficaram em confinamento, o que evitou o desgaste normal das unhas. Não foram observadas alterações dentárias nos animais dos tratamentos CONTNEG e FB 120:1. Porém, conforme a proporção P:F na dieta foi diminuindo, as características relacionadas à fluorose dentária ficaram mais evidentes (sobretudo após 2 anos de suplementação), sendo que os animais que receberam fontes de $\mathrm{P}$ com relação 10:1, apresentaram dentes incisivos permanentes mal formados, quebradiços e com manchas esbranquiçadas. Rosa et al. (1988) também relataram sinais de fluorose dentária em bovinos de corte que receberam fosfato de rocha a partir de 27 meses de suplementação com esse ingrediente.

\section{CONCLUSÕES}

As diferentes fontes de fósforo utilizadas interferiram nos resultados de desempenho dos animais, sendo que o superfosfato triplo foi o que propiciou o melhor ganho de peso após 866 dias de suplementação fosfórica.

Até um ano de suplementação fosfórica com fosfato bicálcico artificialmente fluoretado (P:F 10:1) ou com o fosfato de rocha (P:F 10:1) não houveram danos à saúde ou ao ganho de peso dos animais. Somente após dois anos de suplementação é que os animais que ingeriram tais fontes tiveram lesões dentárias características de fluorose.

Animais que ingerem dietas formuladas com volumosos e concentrados de boa qualidade não deveriam receber suplementação fosfórica, especialmente se os concentrados forem consumidos em mais de $1 \%$ do peso vivo e se o tempo de confinamento for menor que 120 dias.

\section{REFERÊNCIAS}

Baruselli M.S. 2005. Suplementos e co-produtos na nutrição de gado de corte, p.7-22. In: Simpósio sobre desafios e novas tecnologias na bovinocultura de corte (SIMBOI). Brasília. Disponível em <http://www.upis. br/simboi2005/anais/04Suplementosecoprodutos.pdf> Acesso em 21 set. 2012.

Brasil 1997. Procedimentos para Registro de Misturas Minerais. Portaria SDR no 20 de 6 junho de 1997, Ministério da Agricultura e Abastecimento, Brasília, DF. Diário Oficial de 9 de junho de 1997, Seção 1, p.11788. Disponível em <http://extranet.agricultura.gov.br/sislegisconsulta/ consultarLegislacao> Acesso em 21 set. 2012.

Brasil 2000. Atualiza a Portaria SDR no 20 de 6 jan. 1997. Ministério da Agricultura e Abastecimento, Brasília, DF. Diário Oficial da República Federativa do Brasil de 8 fevereiro 2000, Seção 1, p.45-46. Disponível em $<$ http://extranet.agricultura.gov.br/sislegisconsulta/consultarLegislacao> Acesso em 21 set. 2012.

Butolo J.E. 2002. Ingredientes Minerais, p.286-290. In: Butolo J.E. (Ed.), Qualidade de Ingredientes na Alimentação Animal. Colégio Brasileiro de Alimentação Animal, Campinas, SP. 480p.

Conrad J.H., McDowell L.R., Ellis G.L. \& Loosli J.K. 1985. Minerais para ruminantes em pastejo em regiões tropicais. Embrapa-CNPGC, Campo Grande, MS, p.49-50.

Dayrell M.S., Aroeira L.J.M., Silveira M.I. \& Couto R.C.A. 1990. Utilização do fosfato de rocha na alimentação de novilhos em confinamento. Anais 27ạ Reunião da Sociedade Brasileira de Zootecnia, Campinas, SP, p.27.

Godoy S., Chicco C.F. \& Obispo N.E. 2000. Fuentes de fósforo para la alimentación de bovinos: densidad del tejido óseo. Zootecnia Tropical 18(1):29-44.

Gomide J.A. 1994. Exploração de pastagem em solos de baixa fertilidade, p.12-25. In: Peixoto A.M., Moura J.C. \& Faria V.P. (Eds), Pastagens: fundamentos da exploração racional. 2ª ed. FEALQ, Piracicaba. 456p.

Lopes H.O.S., Pereira E.A., Aguiar A.F. \& Abdalla A.L. 1990. Superfosfato triplo como fonte de fósforo suplementar para novilhos de corte em recria. Anais 27 a Reunião da Sociedade Brasileira de Zootecnia. Campinas, SP, p.30.

National Academy of Science 1980. Mineral Tolerance of Domestic Animals. Washington, DC. 534p.

National Research Council 1996. Nutrient Requeriments of Beef Cattle. $6^{\text {th }}$ ed. National Academy Press, Washington, DC. 157p.

Rosa I.V. \& Cardoso J.L.A. 1987. Fósforo, fosfato de rocha e fluorose em bovinos. Bolm Pesq. no 4, Embrapa-CNPGC, Campo Grande, MS. 33p.

Rosa I.V., Cardoso J.L., Souza J.C. \& Gomes R.F. 1988. Uso de fosfato de rocha como fonte de fósforo para bovinos em pastagens. Relatório Bienal de 1986/87 do Convênio Embrapa/Petrofértil, Brasília, DF. 176p.

Sas Institute Inc. 1996. SAS System for Windows, Release 6.12. CD-ROM, Cary, North Caroline, USA.

Silva D.J. \& Queiroz A.C. 2020. Análise de alimentos: Métodos químicos e biológicos. $3^{a}$ ed. Editora UFV, Viçosa. 235p.

Tokarnia C.H., Peixoto P.V., Barbosa J.D., Brito M.F. \& Döbereiner J. 2010. Deficiências Minerais em Animais de Produção. Editora Helianthus, Rio de Janeiro. 191p.

Veloso J.A.F. 1991. Perspectivas de uso dos fosfatos de rocha nacionais na alimentação animal. Cad. Téc. Esc. Vet. UFMG 6:55-84.

Vitti D.M.S.S., Abdalla A.L. \& Filho J.C.S. 1989. Fontes alternativas de fósforo para ruminantes: Absorção real e disponibilidade biológica. Arq. Bras. Med. Vet. Zootec. 41(6):503-10.

Vitti D.M.S.S., Abdalla A.L. \& Filho J.C.S. 1991. Avaliação da disponibilidade biológica do fósforo do fosfato bicálcico e de fosfato de rocha para ovinos com o uso de radiofósforo $\left({ }^{32} \mathrm{P}\right)$ como traçador. Pesq. Agropec. Bras. 26(8):1113-1118. 